\title{
Glomus clarum e G. etunicatum: cultivo em solo e aeroponia ${ }^{1}$
}

\author{
LAURA M. PAIVA ${ }^{2,4}$, MARYLUCE A. SILVA ${ }^{2}$, PAULO C. SILVA ${ }^{3}$ e LEONOR C. MAIA ${ }^{2}$
}

(recebido: 1 de março de 2002; aceito: 9 de abril de 2003)

\begin{abstract}
Glomus clarum Nicol. \& Schenck and G.etunicatum Becker \& Gerd.: cultivated in soil and aeroponic culture). The production of inoculum of the arbuscular mycorrhizal fungi (AMF) Glomus clarum and G. etunicatum in soil and aeroponic culture was evaluated in a greenhouse. The experiment design was in a factorial arrangement of $2 \times 2 \times 5$, representing: 2 inoculation treatments (Glomus clarum and G. etunicatum) $\times 2$ culture systems (soil and aeroponic) $\times 5$ evaluation periods $(0,30,60,90$, and 120 days $)$, with 5 replicates. Shoots of sweet potato, disinfested with sodium hypochlorine, were planted in 120 pots with sterilized soil + vermiculite. Half of the plants was inoculated with 50 spores of $G$. clarum and the remaining 60 ones, with 50 spores of $G$. etunicatum. After 64 days, half of the plants was transferred to aeroponic chambers (one for each fungus) with nutrient solution, applied through micro aspersion during 1' and intervals of 3'. Root colonization and production of spores were evaluated in 0, 30, 60, 90, and 120 days. G. clarum promoted extensive root colonization, when compared to G. etunicatum, while the production of spores was similar between both. Higher levels of colonization and sporulation were obtained in the soil culture, with the best cultivation period after 60 days, independently of the fungus. Although in general higher inoculum production was obtained in soil, the aeroponic system is also promising, mostly if the AMF is maintained for 90 days of growth.
\end{abstract}

Key words - Colonization, endomycorrhizal fungi, Glomales, Glomus, sporulation

RESUMO - (Glomus clarum Nicol. \& Schenck e G. etunicatum Becker \& Gerd.: cultivo em solo e aeroponia). Foi avaliada em casa de vegetação, a produção de inóculo dos fungos micorrízicos arbusculares (FMA) Glomus clarum e G. etunicatum em cultura aeropônica e em solo. O experimento foi conduzido em delineamento inteiramente casualizado com arranjo fatorial de $2 \times 2 \times 5$, sendo: 2 tratamentos relativos à inoculação (Glomus clarum e G. etunicatum) $\times 2$ sistemas de cultivo (solo e aeroponia $) \times 5$ períodos de avaliação $(0,30,60,90$ e 120 dias $)$ e cinco repetições. Ramas de batata-doce desinfestadas com hipoclorito de sódio foram plantadas em 120 potes com solo + vermiculita, sendo a metade inoculada com 50 esporos de G. clarum e o restante com 50 esporos de G. etunicatum. Após 64 dias, metade das plantas foi transferida para câmaras aeropônicas (uma para cada fungo) contendo água destilada + solução nutritiva a pH 6,0. A solução nutritiva foi aplicada por microaspersão por um minuto com intermitência de três minutos. A colonização das raízes e a produção de esporos foram avaliadas aos $0,30,60,90$ e 120 dias de crescimento. G. clarum promoveu extensiva colonização das raízes quando comparado a G. etunicatum,com densidade de esporos semelhantes. Maiores níveis de esporulação e colonização foram obtidos no cultivo em solo, com melhor tempo de cultivo aos 60 dias, independentemente do FMA. No entanto, a maior produção de inóculo foi obtida no solo, apesar do sistema aeropônico também ter sido bastante promissor aos FMA, principalmente aos 90 dias de crescimento.

Palavras-chave - Colonização, esporulação, fungos endomicorrízicos, Glomales, Glomus

\section{Introdução}

Os fungos micorrízicos arbusculares (FMA) associam-se simbioticamente a raízes de plantas, formando as micorrizas arbusculares. São atribuídas a essa simbiose a capacidade de melhorar o estado nutricional das plantas, ampliar sua adaptação a

\footnotetext{
1. Parte da Tese de Doutorado da primeira autora, Centro de Ciências Biológicas, UFPE.

2. Universidade Federal de Pernambuco, Centro de Ciências Biológicas, Departamento de Micologia, Av. Prof. Nelson Chaves, s/n, 50670-420 Recife, PE, Brasil.

3. Faculdade de Ciências Agrárias e Veterinárias, Unesp, Rod. Paulo Donato Castelani, s/n, 14870-000 Jaboticabal, SP, Brasil.

4. Autor para correspondência: mesquita@truenet.com.br
}

diferentes ecossistemas e aumentar a tolerância a fatores estressantes bióticos e abióticos (Saggin Júnior \& Lovato 1999). Em vista dos benefícios propiciados aos hospedeiros, os FMA são de grande interesse para as regiões tropicais, especialmente para o Brasil, devido sobretudo às condições ambientais e à baixa fertilidade de muitos dos solos aqui encontrados (Siqueira 1994).

Apesar dos inúmeros trabalhos (Araújo et al. 1994, Siqueira et al. 1994, Souza \& Silva 1996) que demonstram a utilização dos FMA com os benefícios para os cultivares de importância econômica, alguns problemas limitam a utilização generalizada deste insumo biológico. Um deles tem sido o fato destes fungos somente viverem em associação com raízes metabolicamente ativas, isto é, não são cultivados "in vitro" e, provavelmente, por isso, não foi desenvolvida 
tecnologia eficiente para a produção massal destes microrganismos. A produção de inóculo fica assim restrita a métodos que envolvam o crescimento conjunto do fungo com a planta.

Entre os métodos propostos, há o de "cultura em potes", onde a planta e o fungo são mantidos em potes com solo (Menge 1983). Meios excluindo solo também têm sido usados: cultura hidropônica (Ojala \& Jarrell 1980); filme nutritivo (Howeler et al. 1981); "pellets" de argila (Dehne \& Backhaus 1986) e aeroponia (Sylvia \& Hubbell 1986, Jarstfer \& Sylvia 1992); entretanto, nenhum desses foi definido como de uso generalizado.

O sistema de cultivo aeropônico tem como característica o crescimento de raízes expostas constantemente a uma fina camada de mistura definida de nutrientes e água, como substrato, e foi inicialmente proposto por Zobel et al. (1976). Esse sistema tem se mostrado promissor na multiplicação de esporos e na produção de raízes que, crescendo na ausência de solo, apresentam-se limpas e sem a contaminação por nematóides e insetos (Hung \& Sylvia 1988).

Devido à necessidade da produção regular de inóculo de FMA, os estudos nessa área vêm sendo gradativamente ampliados, com alguns relacionados ao cultivo aeropônico (Sylvia \& Hubbell 1986, Hung \& Sylvia 1988, Jarstfer \& Sylvia 1992, Sylvia \& Jarstfer 1994, Wu et al. 1995, Souza et al. 1996, Martin-Laurent et al. 1999, Mohammad et al. 2000). Este trabalho teve como objetivo avaliar a produção de inóculo de Glomus clarum e G. etunicatum em cultura aeropônica e em solo.

\section{Material e métodos}

O experimento foi conduzido em casa de vegetação e no Laboratório de Micorrizas do Departamento de Micologia da Universidade Federal de Pernambuco.

Como substratos foram utilizados: a) solo Latossolo Amarelo Distrófico Argissólico, esterilizado, 20 dias antes da utilização, por fumigação com Bromex (brometo de metila 980 g. $\mathrm{kg}^{-1}$ e cloropicrina 20 g. $\mathrm{kg}^{-1}$ ). As análises física e química do solo foram realizadas pela Empresa Pernambucana de Pesquisa Agropecuária (IPA). O solo, do tipo franco arenoso, tem as seguintes características: $\mathrm{pH} 5,7 ; \mathrm{P} 4$ mg.dm-3 $; 1,9 ; 0,7 ; 0,12 ; 0,10 ; 0,06 \mathrm{cmol}_{\mathrm{c}} \cdot \mathrm{dm}^{-3}$ respectivamente de $\mathrm{Ca}, \mathrm{Mg}, \mathrm{K}, \mathrm{Al}, \mathrm{Na}$. b) solução nutritiva utilizada no sistema de cultura aeropônica, recomendada por Jarstfer \& Sylvia (1992), com a seguinte composição química: $\mathrm{KH}_{2} \mathrm{PO}_{4}(0,01$ $\mathrm{M}) ; \mathrm{KNO}_{3}(1 \mathrm{M} 101)$; NaFeEDTA (1 M); $\mathrm{Ca}\left(\mathrm{NO}_{3}\right)_{2}(1 \mathrm{M})$; $\mathrm{NaCl}(0,1 \mathrm{M}) ; \mathrm{Mg} \mathrm{SO}_{4}(1 \mathrm{M}) ; \mathrm{H}_{3} \mathrm{BO}_{3}(50 \mathrm{mM}) ; \mathrm{MnCl}_{2} .4 \mathrm{H}_{2} \mathrm{O}$ $(1 \mathrm{mM}) ; \mathrm{ZnSO}_{4} .5 \mathrm{H}_{2} \mathrm{O}(0,7 \mathrm{mM}) ; \mathrm{CuSO}_{4} \cdot 5 \mathrm{H}_{2} \mathrm{O}(3 \mathrm{mM})$; $\mathrm{Na}_{2} \mathrm{MoO}_{4} \cdot 2 \mathrm{H}_{2} \mathrm{O}(0,07 \mathrm{mM})$.
O experimento foi conduzido em delineamento inteiramente casualizado, em arranjo fatorial de $2 \times 2 \times 5$, sendo: 2 tratamentos de inoculação (Glomus clarum Nicol. $\&$ Schenck e G. etunicatum Becker \& Gerd.) $\times 2$ sistemas de cultura (solo e aeroponia) $\times 5$ períodos de avaliação $(0,30$, 60, 90 e 120 dias), com 5 repetições.

Para a propagação e inoculação foram utilizadas ramas de batata-doce (Ipomoea batatas (L.) Lam.) variedade Co-branca, fornecidas pelo IPA, com segmentos de aproximadamente $15 \mathrm{~cm}$ de comprimento, desinfestadas com solução de hipoclorito de sódio (1:100) por sete minutos. As ramas foram plantadas em 120 potes plásticos $(2 \mathrm{~kg})$, tendo como substrato uma mistura de solo + vermiculita (2:1 v.v), sendo a metade inoculada com 50 esporos de Glomus clarum e o restante inoculado com 50 esporos de G. etunicatum. Os inóculos foram cedidos pela Embrapa (Centro Nacional de Pesquisa em Agrobiologia) e registrados sob números UFPE 6 e 8 , respectivamente, e multiplicados em painço (Panicum miliaceum L.).

Diariamente foram registrados os valores de temperatura e umidade relativa do ar, em termohigrômetro (TFA, Alemanha), obtendo-se os valores máximos de $35,9^{\circ} \mathrm{C}$ e $92 \%$ e mínimos de $27,2^{\circ} \mathrm{C}$ e $56 \%$, respectivamente.

Sessenta e quatro dias após o plantio, constatada a colonização das plantas utilizando-se a técnica de interseção dos quadrantes (Giovannetti \& Mosse 1980), metade permaneceu nos potes e as demais foram transferidas para duas câmaras aeropônicas (uma para Glomus clarum, uma para G. etunicatum) montadas em tanques de amianto (Brasilit), contendo $200 \mathrm{~L}$ de água destilada mais $1 \mathrm{~L}$ de solução nutritiva (Jarstfer \& Sylvia 1992). Com auxílio de um conjunto de microaspersores, as plantas receberam solução nutritiva por pulverização durante um minuto, com intermitência de três minutos, o que permitiu o crescimento do sistema radicular suspenso em atmosfera arejada. Associada ao sistema, foi instalada uma fonte luminosa (GRO-LUX F-30T12), a $70 \mathrm{~cm}$ de altura das plantas para aumentar o fotoperíodo e estimular o crescimento e a multiplicação dos FMA. $\mathrm{O}$ pH foi ajustado diariamente para 6,0 utilizando-se soluções de $\mathrm{HCl}(1 \%)$ ou $\mathrm{NaOH}(0,1 \mathrm{~N})$.

A colonização das raízes, bem como a produção de esporos foram avaliados aos 0, 30, 60, 90, e 120 dias, considerando o momento de instalação do sistema aeropônico. Cinco plantas, por tratamento, foram coletadas em cada ocasião. As raízes foram lavadas, clarificadas com $\mathrm{KOH}(10 \%)$ e coradas com azul-de-Tripano em lactoglicerol 0,05\% (Phillips \& Hayman 1970) e, para a análise de colonização, utilizou-se a técnica de interseção dos quadrantes (Giovannetti \& Mosse 1980).

Para avaliação da densidade de esporos (DE), foram utilizados $100 \mathrm{~g}$ de solo de cada pote aos 0,30, 60, 90 e 120 dias de crescimento. O solo foi processado pelo método de peneiramento úmido (Gerdemann \& Nicolson 1963) utilizando-se peneiras com aberturas de 0.105 e $0.045 \mu \mathrm{m}$, seguido de centrifugação em água e sacarose a 40\% (Jenkins 1964). 
Para avaliação da esporulação no sistema aeropônico recolheram-se $100 \mathrm{~g}$ de raízes, que foram lavadas cuidadosamente para obtenção dos esporos aderidos. Em ambos os sistemas (solo e aeroponia), os esporos foram recolhidos em peneiras de $0,045 \mu \mathrm{m}$ de abertura, transferidos para placa canaletada e contados em microscópio estereoscópico (40 x).

Os dados foram submetidos à análise da variância e as médias comparadas pelo teste de Tukey $(\mathrm{P}<0,05)$. As análises foram efetuadas usando o programa ESTAT, do Departamento de Ciências Exatas da Faculdade de Ciências Agrárias e Veterinárias (FCAV/UNESP), Campus de Jaboticabal, SP.

\section{Resultados}

Foram observadas diferenças significativas $(\mathrm{P}<0,01)$ para as variáveis densidade de esporos $(\mathrm{DE})$ e colonização de raízes $(\mathrm{CR})$ em relação a substrato e período de cultivo. No entanto, apenas a colonização de raízes, e não a esporulação, diferiu significativamente entre os fungos, com Glomus clarum colonizando mais extensivamente o hospedeiro do que G. etunicatum. Por outro lado, a interação entre os FMA e os períodos de cultivo foi significativa para ambos, colonização e densidade de esporos, enquanto a interação fungo, substrato e período foi representativa apenas para densidade de esporos.

O desdobramento das interações indicou que o período de cultivo interferiu na esporulação e colonização produzida por ambos os fungos, nos dois substratos $(\mathrm{P}<0,01)$. Em relação aos tempos de cultivo, somente no início, quando as plantas foram transplantadas para a aeroponia e aos 120 dias foram observadas diferenças significativas $(\mathrm{P}<0,01)$ em relação à densidade de esporos.

Independentemente do substrato e do período de cultivo, os dois fungos tiveram produção similar de esporos, o que não ocorreu nos resultados da colonização (tabela 1).

Em geral, maiores níveis de colonização e esporulação foram obtidos nos tratamentos em solo do que naqueles em sistema aeropônico (tabela 2). Observando isoladamente, a produção de esporos no sistema em solo foi elevada dos 30 aos 90 dias, enquanto houve decréscimo acentuado 30 dias após a mudança do solo para o sistema aeropônico. Por outro lado, os FMA recuperaram a capacidade de esporulação, que foi elevada aos 60 dias; a partir de 90 dias a produção começou a declinar, atingindo índice reduzido aos 120 dias.
Tabela 1. Comparação entre médias referentes à densidade de esporos (DE) de FMA e colonização de raízes (CR) de batata-doce mantidas em solo e aeroponia por 120 dias. Médias seguidas da mesma letra, na coluna, não diferem estatisticamente pelo teste de Tukey $(\mathrm{P}>0,05)$.

Table 1. Comparison of means of AMF (FMA) spore density (DE) and root colonization (CR) of sweet potato cultivated in soil and aeroponic for 120 days. Means followed by the same latter, in column, are not statistically different (Tukey test $\mathrm{P}>0,05$ ).

\begin{tabular}{lrc}
\hline Causas da variação & $\mathrm{DE}\left(100 \mathrm{~g}^{-1}\right)$ & $\mathrm{CR}(\%)$ \\
\hline FMA & & \\
Glomus clarum & $834,44 \mathrm{a}$ & $73,74 \mathrm{a}$ \\
Glomus etunicatum & $895,82 \mathrm{a}$ & $70,60 \mathrm{~b}$ \\
Substratos & & \\
Solo & $909,72 \mathrm{a}$ & $74,30 \mathrm{a}$ \\
Aeroponia & $820,54 \mathrm{~b}$ & $70,04 \mathrm{~b}$ \\
Períodos de cultivo (dias) & & \\
Tempo 0 & $428,10 \mathrm{c}$ & $60,40 \mathrm{~d}$ \\
Tempo 30 & $564,35 \mathrm{c}$ & $59,30 \mathrm{~d}$ \\
Tempo 60 & $1639,55 \mathrm{a}$ & $88,55 \mathrm{a}$ \\
Tempo 90 & $1251,25 \mathrm{~b}$ & $83,35 \mathrm{~b}$ \\
Tempo 120 & $442,40 \mathrm{c}$ & $69,25 \mathrm{c}$ \\
\hline
\end{tabular}

As plantas mantidas nos dois sistemas de cultura apresentaram maior colonização de raízes aos 60 dias de cultivo e esta manteve-se elevada até os 90 dias. Houve aumento da colonização das plantas mantidas no solo até os 60 dias, com decréscimo posterior. No sistema aeropônico a colonização diminuiu com o transplante das plantas para a aeroponia, tal como ocorreu na esporulação e, mais uma vez, observou-se a recuperação da atividade dos fungos, com aumento significativo da colonização, que se manteve elevada até os 90 dias, começando a declinar aos 120 dias.

\section{Discussão}

Os fungos não apresentaram diferença quanto à produção de esporos em ambos os substratos. O mesmo não ocorreu com o índice de colonização das raízes, que foi mais elevado em solo, sendo que, em ambos, esse índice foi maior que $70 \%$. A colonização produzida por Glomus clarum também foi maior que a observada nas plantas colonizadas por G. etunicatum. Sylvia \& Hubbell (1986) observaram 75\% de colonização produzida por $G$. mosseae Gerd. \& Trappe em raízes de Paspalum notatum Flügge, após 60 dias em cultivo aeropônico. Avaliando a micorrização de plantas de 
batata-doce mantidas em sistema aeropônico com Glomus etunicatum, Gigaspora margarita Becker \& Hall e Entrosphospora colombiana Spain \& Schenck, Souza et al. (1996) observaram de $53 \%$ a $64 \%$ de colonização após 56 até 72 dias, índices menores que os aqui registrados.

Tabela 2. Comparação entre médias do desdobramento das interações fungos, substratos e tempos, para as variáveis densidade de esporos (DE) e porcentagem de colonização de raízes (CR) de batata-doce inoculadas com Glomus clarum e G. etunicatum. Médias seguidas da mesma letra na coluna, não diferem estatisticamente pelo teste de Tukey $(\mathrm{P}>0,05)$.

Table 2. Comparison of means of the relationships between fungus, substrate and time versus spore density (DE) and root colonization (CR) of sweet potato inoculated with Glomus clarum and G. etunicatum. Means followed by the same latter, in column, are not statistically different (Tukey test $\mathrm{P}>0,05$ ).

\begin{tabular}{lcc}
\hline Causas da variação & DE $(100 \mathrm{~g}-1)$ & CR $(\%)$ \\
\hline Tempo 0 vs. G. clarum & $170,8 \mathrm{~b}$ & $62,2 \mathrm{c}$ \\
Tempo 30 vs. G. clarum & $452,4 \mathrm{c}$ & $59,5 \mathrm{c}$ \\
Tempo 60 vs. G. clarum & $1502,5 \mathrm{a}$ & $83,4 \mathrm{a}$ \\
Tempo 90 vs. G. clarum & $1459,3 \mathrm{a}$ & $89,3 \mathrm{a}$ \\
Tempo 120 vs. G. clarum & $587,2 \mathrm{~b}$ & $74,3 \mathrm{~b}$ \\
Tempo 0 vs. G. etunicatum & $685,4 \mathrm{bc}$ & $58,6 \mathrm{c}$ \\
Tempo 30 vs. G. etunicatum & $676,3 \mathrm{c}$ & $59,1 \mathrm{c}$ \\
Tempo 60 vs. G. etunicatum & $1776,6 \mathrm{a}$ & $93,7 \mathrm{a}$ \\
Tempo 90 vs. G. etunicatum & $1043,2 \mathrm{ab}$ & $77,4 \mathrm{~b}$ \\
Tempo 120 vs. G. etunicatum & $297,6 \mathrm{c}$ & $64,2 \mathrm{c}$ \\
Tempo 0 vs. Solo & $428,1 \mathrm{c}$ & $60,4 \mathrm{c}$ \\
Tempo 30 vs. Solo & $1058,9 \mathrm{ab}$ & $74,4 \mathrm{~b}$ \\
Tempo 60 vs. Solo & $1252,6 \mathrm{a}$ & $89,7 \mathrm{a}$ \\
Tempo 90 vs. Solo & $1217,7 \mathrm{a}$ & $80,3 \mathrm{~b}$ \\
Tempo 120 vs. Solo & $591,3 \mathrm{bc}$ & $66,7 \mathrm{c}$ \\
Tempo 0 vs. Aeroponia & $428,1 \mathrm{~b}$ & $60,4 \mathrm{c}$ \\
Tempo 30 vs. Aeroponia & $69,8 \mathrm{c}$ & $44,2 \mathrm{~d}$ \\
Tempo 60 vs. Aeroponia & $2026,5 \mathrm{a}$ & $87,4 \mathrm{a}$ \\
Tempo 90 vs. Aeroponia & $1284,8 \mathrm{a}$ & $86,4 \mathrm{a}$ \\
Tempo 120 vs. Aeroponia & $293,5 \mathrm{~b}$ & $71,8 \mathrm{~b}$ \\
Solo vs. Tempo 0 & $428,1 \mathrm{a}$ & $60,4 \mathrm{a}$ \\
Aeroponia vs. Tempo 0 & $428,1 \mathrm{a}$ & $60,4 \mathrm{a}$ \\
Solo vs. Tempo 30 & $1058,9 \mathrm{a}$ & $74,4 \mathrm{a}$ \\
Aeroponia vs. Tempo 30 & $69,8 \mathrm{~b}$ & $44,2 \mathrm{~b}$ \\
Solo vs. Tempo 60 & $1252,6 \mathrm{a}$ & $89,7 \mathrm{a}$ \\
Aeroponia vs. Tempo 60 & $2026,5 \mathrm{a}$ & $87,4 \mathrm{a}$ \\
Solo vs. Tempo 90 & $1217,7 \mathrm{a}$ & $80,3 \mathrm{~b}$ \\
Aeroponia vs. Tempo 90 & $1284,8 \mathrm{a}$ & $86,4 \mathrm{a}$ \\
Solo vs. Tempo 120 & $591,3 \mathrm{a}$ & $66,7 \mathrm{~b}$ \\
Aeroponia vs. Tempo 120 & $293,5 \mathrm{~b}$ & $71,8 \mathrm{a}$ \\
\hline & &
\end{tabular}

Durante os primeiros 30 dias de cultivo em aeroponia, as plantas sofreram estresse de adaptação, com redução significativa na taxa de colonização radicular e no número de esporos; após este período, ambos aumentaram consideravelmente, o que também foi evidenciado por Souza et al. (1996).

Grandes concentrações de esporos têm sido produzidas em sistemas aeropônicos quando comparados a produção em potes com solo. Isso provavelmente ocorre porque esses sistemas encontram-se isentos de contaminantes, tais como hiperparasitas e bactérias, além de terem o $\mathrm{pH}$ regularmente ajustado e solução nutritiva com baixas concentrações de fósforo (Sylvia \& Jarstfer 1994).

Utilizando raízes de Ipomoea batatas colonizadas com Glomus sp., Sylvia \& Jarstfer (1992) obtiveram mais de 135.000 propágulos por grama de matéria seca de raiz, em cultivo aeropônico, observando que a colonização das raízes pelo FMA foi afetada pelo $\mathrm{pH}$ da solução, que deve ser ajustado tanto para a planta como para o fungo.

A maior produção de esporos ocorreu aos 60 dias de cultivo, em ambos os sistemas de cultivo. Esses resultados foram semelhantes aos obtidos em raízes de Paspalum notatum e Ipomoea batatas associados a Entrophospora kentinensis Wu \& Liu. Naquele experimento, após 45 dias do transplantio para o sistema aeropônico, o fungo apresentou elevada produção de sáculos esporíferos (Wu et al. 1995).

A produção de inóculo de Glomus deserticola Trappe \& Menge, G. etunicatum e G. intraradices Schenck \& Smith em cultivo aeropônico, associados a Paspalum notatum e Ipomoea batatas foi de 50\%, 45\% e $20 \%$, respectivamente, obtida após 90 dias, vindo a declinar após 105 dias (Hung \& Sylvia 1988). Esse resultado foi semelhante ao aqui obtido, onde a produção de esporos começou a decair aos 120 dias de cultivo.

A produção de inóculo em cultivo com areia e vermiculita, bem como em sistemas hidropônicos modificados, também pode resultar na obtenção de elevadas quantidades de propágulos em relação ao cultivo em solo, permitindo melhor controle das condições físicas e químicas do meio de crescimento e maior aeração. Entretanto, uma desvantagem é a não fixação dos nutrientes, sendo necessária a aplicação de soluções nutritivas diluídas a intervalos regulares (Saggin Júnior \& Lovato 1999).

Empregando areia e vermiculita suplementada com solução nutritiva, Millner \& Kitt (1992) obtiveram cerca de 235 e 44 esporos, por grama de substrato, de Glomus etunicatum e Gigaspora margarita Becker \& Hall, 
respectivamente, mostrando que esse sistema pode ser um bom substrato para a produção de esporos de FMA.

A duração do experimento é fator importante na quantificação do número de esporos produzidos (Luedders et al. 1979). No presente caso, as plantas foram colhidas porque iriam atingir a fase de floração, que é entre 120 a 150 dias, não sendo recomendável prolongar o experimento. No decorrer do ciclo fisiológico do hospedeiro ocorrem diferenças na produção dos hormônios, influenciando a esporulação, o estabelecimento e a eficiência da simbiose micorrízica (Barea \& Azcón-Aguilar 1982).

Embora em termos gerais a produção de inóculo tenha sido melhor no sistema de pote de cultura em solo, o aeropônico também é promissor, sobretudo se o fungo for mantido no sistema por no máximo 90 dias, além de ser produzido em condições livres dos contaminantes que podem ocorrer no solo, mesmo após este ter sido desinfestado.

Agradecimentos - Ao Conselho Nacional de Desenvolvimento Científico e Tecnológico (CNPq), pelo suporte financeiro e pelas bolsas de M.A. Silva - Pibic e L.C. Maia - Pesquisa.

\section{Referências bibliográficas}

ARAÚJO, A.P., SILVA, E.M.R. \& ALMEIDA, D.L. 1994. Efetividade de fungos endomicorrízicos em tomateiro em diferentes níveis de fósforo no solo. Revista Brasileira de Ciência do Solo 18:193-199.

BAREA, J.M. \& AZCÓN-AGUILAR, C. 1982. Production of plant growth-regulating substances by the vesiculararbuscular mycorrhizal fungus Glomus mosseae. Applied and Environmental Microbiology 43:810-813.

DEHNE, H.W. \& BACKHAUS, G.F. 1986. The use of vesiculararbuscular mycorrhizal fungi in plant production. I. Inoculum production. Journal Plant Disease Protecion 93:415-424.

GERDEMANN, J.W. \& NICOLSON, T.H. 1963. Spores of mycorrhizal Endogone species extracted from soil by wet sieving and decanting. Transactions of the British Mycological Society 46:235-244.

GIOVANNETTI, M. \& MOSSE, B. 1980. An evaluation of techniques for measuring vesicular arbuscular mycorrhizal infection in roots. New Phytologist 84:489-500.

HOWELER, R.H., EDWARDS, D.G. \& ASHER, C.J. 1981. Application of the flowing solution culture technique to studies involving mycorrhizas. Plant and Soil 59:179-183.

HUNG, L.L. \& SYLVIA, D.M. 1988. Production of vesiculararbuscular mycorrhizal fungus inoculum in aeroponic culture. Applied and Environmental Microbiology 54:353-357.
JARSTFER, A.G. \& SYLVIA, D.M. 1992. Inoculum production and inoculation strategies for vesiculararbuscular mycorrhizal fungi. In Soil microbial ecology: Applications in agricultural and environmental management (F.B. Metting, ed.). Marcel Dekker, Inc., New York, p.349-377.

JENKINS, W.R. 1964. A rapid centrifugal-flotation technique for separating nematodes from soil. Plant Disease Report 48:692.

LUEDDERS, V.D., CARLING, D.E. \& BROWN, M.F. 1979. Effect of soybean plant growth on spore production by Glomus mosseae. Plant and Soil 53:393-397.

MARTIN-LAURENT, F., LEE, S.K., THAM, F.Y., JIE, H. \& DIEM, H.G. 1999. Aeroponic production of Acacia mangium inoculated with AM fungi for reflorestation in the tropics. Forest Ecology and Management 122:199-207.

MENGE, J.A. 1983. Utilization of vesicular-arbuscular mycorrhizal fungi in agriculture. Canadian Journal of Botany 61:1015-1024.

MILLNER, P.D. \& KITT, D.G.1992. The Beltsville method for soiless production of vesicular-arbuscular mycorrhizal fungi. Mycorrhiza 2:9-15.

MOHAMMAD, A., KHAN, A.G. \& KUEK, C. 2000. Improved aeroponic culture of inocula of arbuscular mycorrhizal fungi. Mycorrhiza 9:337-339.

OJALA, J.C. \& JARRELL, W.M. 1980. Hydroponic sand culture system for mycorrhizal research. Plant and Soil 57:297-303.

PHILliPS, J.M. \& HAYMAN, D.S. 1970. Improved procedures for clearing roots and staining parasitic and vesicular arbuscular mycorrhizal fungi for rapid assessment of infections. Transactions of the British Mycological Society 55:158-161.

SAGGIN JÚNIOR, O.J. \& LOVATO, P.E. 1999. Aplicação de micorrizas na produção de mudas micropropagadas. In Inter-relação fertilidade, biologia do solo e nutrição de plantas (J.O. Siqueira, F.M.S. Moreira, A.S. Lopes, L.R.G. Guilerme, V. Faquim \& A.E. Furtini, eds.). Sociedade Brasileira de Ciência do Solo, UFLA, DCS, Lavras, p.725-773.

SIQUEIRA, J.O. 1994. Micorrizas arbusculares. In Microorganismos de importância agrícola (R.S. Araújo \& M. Hungria, eds.). Embrapa/CNPAF, Brasília 44:151-194.

SIQUEIRA, J.O., COLOZZI FILHO, A. \& SAGGIN JÚNIOR, O.J. 1994. Efeitos da infecção de plântulas de cafeeiro com quantidades crescentes de esporos do fungo endomicorrízico Gigaspora margarita. Pesquisa Agropecuária Brasileira 19:875-883.

SOUZA, E.S., BURITY, H.A., SANTO, A.C.P.E. \& SILVA, M.L.R.B. 1996. Alternative for mycorrhizal fungi inoculum production in aeroponic culture. Pesquisa Agropecuária Brasileira 31:153-158. 
SOUZA, F.A. \& SILVA, E.M. 1996. Micorrizas arbusculares na revegetação de áreas degradadas. In Avanços em fundamentos e aplicação de micorrizas (J.O. Siqueira, ed.). UFLA/DCS, DCF, Lavras, p.255-290.

SYLVIA, D.M. \& HUBBELL, D.H. 1986. Growth and sporulation of vesicular-arbuscular mycorrhizal fungi in aeroponic and membrane systems. Symbiosis 1:259-267.

SYLVIA, D.M. \& JARSTFER, A.G. 1992. The production and introduction of arbuscular mycorrhizal fungi in the native plant nursery. Florida Agricultural Experiment Station, Florida.
SYLVIA, D.M. \& JARSTFER, A.G. 1994. Production of inoculum and inoculation with arbuscular mycorrhizal fungi. In Management of mycorrhizas in agriculture, horticulture and forestry (A.D. Robson \& N. Malajczuk, eds.). Academic Publishers, Dordrecht, p.231-238.

WU, C.G., LIU, Y.S. \& HUNG, L.L. 1995. Spore development of Entrophospora kentinensis in an aeroponic system. Mycologia 87:582-587.

ZOBEL, R.W., TREDICE, P.D. \& TORREY, J.G. 1976. Methods for growing plants aeroponically. Plant Physiology 57:344-346. 